\title{
Diabetic kidney disease: Act now or pay later
}

Robert C Atkins and Paul Zimmet

For the 2010 International Society of Nephrology/ International Federation of Kidney Foundations World Kidney Day Steering Committee* (RA) and the International Diabetes Federation (PZ)

Este editorial foi modificado em 02/07/2010 em função de padronização das referências.

\section{World Kidney Day 11 March 2010: we must act on diabetic kidney disease}

In 2003, the International Society of Nephrology and the International Diabetes Federation launched a booklet called "Diabetes in the Kidney: Time to act" [1] to highlight the global pandemic of type 2 diabetes and diabetic kidney disease. It aimed to alert governments, health organisations, providers, doctors and patients to the increasing health and socio-economic problems due to diabetic kidney disease and its sequelae, end stage kidney disease requiring dialysis and cardiovascular death. Seven years later, the same message has become even more urgent. World Kidney Day 2010, under the auspices of the International Society of Nephrology (ISN) and the International Federation of Kidney Foundations IFKF), together with the International Diabetes Federation(IDF), provides yet another chance to underline the importance of diabetic kidney disease, stress its lack of awareness at both public and government levels and emphasise that its management involves prevention, recognition and treatment of its complications. Primary prevention of type 2 diabetes will require massive lifestyle changes in the developing and developed world supported by strong governmental commitment to promote lifestyle and societal change.

\section{The Global Threat of Type 2 Diabetes}

The 21st century has the most diabetogenic environment in human history [2, 3]. Over the past 25 years or so, the prevalence of type 2 diabetes in the USA has almost doubled, with three- to five-fold increases in India, Indonesia, China, Korea and Thailand [4]. In 2007, there were 246 million people with diabetes in the world, but by 2025, that number is estimated to reach 380 million [5]. People with impaired glucose tolerance, a "prediabetic state" numbered 308 million in 2007 and will increase to 418 million by 2025 [5]. The increase in prevalence of diabetes will be greater in the developing countries. In Mexico for example, $18 \%$ of its adult population will have with type 2 diabetes by 2025. According to the $\mathrm{WHO}$, China and India will have about 130 million diabetics by 2025 who will consume about $40 \%$ of their country's healthcare budget in addition to reducing productivity and hindering economic growth.

It was against this background that on December 21st 2006, the United Nations General Assembly unanimously passed Resolution 61/225 declaring diabetes an international public health issue and identifying World Diabetes Day as a United Nations Day, only the second disease after HIV/AIDS to attain that status. For the first time, governments have acknowledged that a non-infectious disease poses as serious a threat to world health as infectious diseases like HIV/AIDS, tuberculosis and malaria. The problems of diabetes are now seen as a major global public health concern, especially in the developing world which can least afford it. The first step to act on diabetic kidney disease must encompass public health campaigns aimed at preventing the development of type 2 diabetes.

\section{Diabetic Kidney Disease}

Diabetes is now the major cause of end stage kidney failure throughout the world in both developed and emerging nations [6]. It is the primary diagnosis causing kidney disease in $20-40 \%$ of people starting treatment for end stage renal disease worldwide [7]. In Australia, new type 2 diabetes patients starting dialysis increased 5-fold between 1993 and 2007 [8]. Between 1983 and 2005, there was a 7-fold increase in new patients starting renal replacement therapy in Japan because of diabetes, accounting for $40 \%$ of all new incidence patients [9]. Thus, some $30 \%$ of the predicted 1.1 trillion dollar medical costs of dialysis world-wide during this decade will result from diabetic nephropathy [10].

In the United Kingdom Prospective Diabetes Study (UKPDS), the rates of progression of newly diagnosed type 2 diabetics between the stages of normoalbuminuria, microalbuminuria, macroalbuminuria and renal failure were 2-3\% per year [11]. Over a median of 15 years of follow-up of 4,000 participants, almost $40 \%$ developed microalbuminuria [12]. In the DEMAND study of 32,208 people 
from 33 countries with known type 2 diabetes attending their family doctor, 39\% had microalbuminuria and prevalence increased with age, duration of diabetes and presence of hypertension [13]). About $30 \%$ of the UKPDS cohort developed renal impairment, of which almost $50 \%$ did not have preceding albuminuria [12]. Reduced glomerular filtration rate and albuminuria caused by diabetic nephropathy are independent risk factors for cardiovascular events and death [14]. Therefore, a strategy to detect early diabetic kidney disease by screening for albuminuria as well as reduced glomerular filtration rate is the second step in taking action on diabetic kidney disease.

An added difficulty to overcome is the remarkable lack of awareness among patients about their condition. In population-based surveys, for every known diabetic patient, there is at least one more that is unknown [15]; only $8.7 \%$ of the general population were able to identify diabetes as a risk factor for kidney disease [16]. For patients with diabetic kidney disease, very few are aware of their condition with some community surveys putting patient awareness of their disease as low as $9.4 \%$, particularly in those with milder impairment [17]. Thus, public education is the third step required for acting on diabetic kidney disease in the community. The IFKF has a long term goal for all kidney patients world-wide to not only be aware of their disease, but to actively know for example their blood pressure and the treatment objectives.

\section{Management of Diabetic Kidney Disease}

There is little use in screening populations or "at risk" groups unless follow up is undertaken and effective treatment is begun and assessed [18]. Fortunately, there is evidence that early therapeutic intervention in patients with chronic kidney disease or diabetes can delay onset of complications and improve outcomes. For example, the UKPDS [19, 20], STENO-2 [21], and ADVANCE studies [22-24] all demonstrated that tight control of blood glucose level, blood pressure (and lipids in STENO-2) significantly reduced incidence and progression of diabetic kidney disease. In people with type 2 diabetes, inhibition of the renin-angiotensin-aldosterone system using an ACE inhibitor or an ARB decreased the progression from normoalbuminuria to microalbuminuria [25], reduced the progression from micro albuminuria to macroalbuminuria,26 and slowed the development of ESRD.27 Thus the use of an ACE inhibitor or ARB is now standard therapy for patients with diabetic nephropathy as well as glucose, lipid and blood pressure control. Effective management using evidence-based therapies is the fourth step in tackling diabetic kidney disease.

The fifth step is development of new therapies. Many new agents are now in clinical trials to reduce renal damage and fibrosis, including blockade of formation of advanced glycation endproducts and other signalling pathways. Other novel agents may potentially prove to be effective in large randomised double-blind clinical trials. 28

\section{How can we Act Now?}

The steps to be taken are clear: campaigns aimed at (1) prevention of type 2 diabetes; (2) screening for early diabetic kidney disease; (3) increasing patient awareness of kidney disease; (4) using medications of proven strategy and finally (5) researching and trialling of new therapies. The ultimate challenge is to get action from primary health care to all higher levels; from the individual patient, to those at risk, in various health jurisdictions, in all countries despite varying economic circumstances and priorities. The problem is a global one and yet requires action at a local level; prevention screening and treatment strategies; education, including increasing awareness both in diabetic patients and those at risk of developing diabetes; and health priorities and governments. Basic research and clinical trials searching for a new understanding and therapies must be supported. 
The United Nations, as noted earlier, recognised the importance of diabetes in 2006 by establishing a World Diabetes Day. Both the ISN and the International Diabetes Federation are working closely with WHO to provide increasing understanding of the challenge that diabetic kidney disease poses to world health and health care budgets. However, World Kidney Day also provides a focus for other international agencies, government ministries of health, non-government organisation, foundations and academic institutions to come together with national kidney foundations to be involved in the effort to prevent and manage diabetic kidney disease.

The ISN through it's COMGAN Research and Prevention Committee has developed a webbased program, the KHDC (for detection and management of chronic kidney disease, hypertension, diabetes and cardiovascular disease in developing countries (http://www.nature.com/isn/education/ guidelines/isn/pdf/ed_051027_2x1.pdf) as a global template involving a detection management and data assessment program which has so far screened some 42,000 people in 25 developing countries and the data are being stored and analyzed at the Kidney Disease Data Center at the committee headquarters at the Mario Negri Institute in Bergamo, Italy. This program can be tailored to any individual country's needs and resources. The IFKF also has a program initiated by the National Kidney Foundation in the USA called the Kidney Early Evaluation Program (KEEP) which is a screening program for people at high risk of kidney disease. KEEP has now been implemented in many countries and will again screen and manage patients with diabetic kidney disease.

The focus on diabetic kidney disease for World Kidney Day 2010 brings awareness of the magnitude of the problem and ramifications for global health for people with diabetes and kidney disease. It is therefore time to act and act urgently. It is time for strategies that prevent diabetes and its sequelae. It is time for programs for health care workers to diagnose and treat people with diabetic kidney disease. It is time for governments to pass legislation to enable the diabetes pandemic to be controlled. After all, diabetic kidney disease, like the epidemics of infectious diseases that have long dominated public health agendas, is potentially preventable. Indeed, March 11, 2010 is time to act on diabetic kidney disease and to sustain that action long after World Kidney Day .

- ISN/IFKF 2010 World Kidney Day Steering Committee: William G Couser, MD, Miguel Riella MD, Co-chairpersons. Georgi Abraham MD, Paul Beerkens, John Feehally MD, Guillermo Garcia-Garcia MD, Dan Larson, Philip KT Li MD, Bernardo Rodriguez-Iturbe, MD

\section{References}

1. International Diabetes Federation and International Society of Nephrology, Diabetes and kidney disease : time to act. 2003: Brussels.

2. Zimmet P, Alberti K, Shaw J. Global and societal implications of the diabetes epidemic. Nature, 2001; 414:782-7.

3. King H, Aubert R, HermanW. Global burden of diabetes, 1995-2025: prevalence, numerical estimates, and projections. Diabetes Care, 1998; 21:1414-31.

4. Yoon KH, Lee JH, Kim JW et al. Epidemic obesity and type 2 diabetes in Asia. Lancet, 2006; 368:1681-8.

5. Sicree R, Shaw J, Zimmet P. Diabetes and impaired glucose tolerance., in Diabetes Atlas, 3rd edition, D. Gan, Editor. 2006, International Diabetes Federation: Brussels. p. 15-109.

6. Reutens AT, Prentice L, Atkins R. The Epidemiology of Diabetic Kidney Disease., in The Epidemiology of Diabetes Mellitus, 2nd Edition, J. Ekoé, et al., Editors. 2008, John Wiley \& Sons Ltd: Chichester. p. 499-518.

7. National Institutes of Health, National Institute of Diabetes and Digestive and Kidney Diseases. International comparisons, in 2007 Annual Data Report: Atlas of Chronic Kidney Disease and End-Stage Renal Disease in the United States. 2007, National Institutes of Health, National Institute of Diabetes and Digestive and Kidney Diseases: Bethesda. p. 239-54. 
8. Appendix II, In McDonald S, Excell L, Livingston B, Editors. ANZDATA Registry Report 2008. 2008, Australia and New Zealand Dialysis and Transplant Registry: Adelaide. p. 1-97.

9. Yamagata K, Iseki K, Nitta K et al. Chronic kidney disease perspectives in Japan and the importance of urinalysis screening. Clin Exp Nephrol, 2008; 12:1-8.

10. Lysaght M. Maintenance dialysis population dynamics: Current trends and long term implications. J Am Soc Nephrol, 2002; 13:S37-40.

11. Adler AI, Stevens RJ, Manley SE et al. Development and progression of nephropathy in type 2 diabetes: the United Kingdom Prospective Diabetes Study (UKPDS 64). Kidney Int 2003; 63:225-32.

12. Retnakaran R, Cull CA, Thorne KI et al. Risk factors for renal dysfunction in type 2 diabetes: U.K. Prospective Diabetes Study 74. Diabetes, 2006; 55:1832-9.

13. Parving HH, Lewis JB, Ravid $\mathrm{M}$ et al. Prevalence and risk factors for microalbuminuria in a referred cohort of type II diabetic patients: a global perspective. Kidney Int, 2006; 69:2057-63.

14. Ninomiya T, Perkovic V, de Galan BE et al. Albuminuria and kidney function independently predict cardiovascular and renal outcomes in diabetes. J Am Soc Nephrol, 2009; 20:1813-21.

15. Dunstan DW, Zimmet PZ, Welborn TA et al. The rising prevalence of diabetes and impaired glucose tolerance: the Australian Diabetes, Obesity and Lifestyle Study. Diabetes Care, 2002; 25:829-34.

16. White SL, Polkinghorne KR, Cass A et al. Limited knowledge of kidney disease in a survey of AusDiab study participants. Med J Aust, 2008; 188:204-8.

17. Whaley-Connell A, Sowers JR, McCullough PA et al. Diabetes mellitus and CKD awareness: the Kidney Early Evaluation Program (KEEP) and National Health and Nutrition Examination Survey (NHANES). Am J Kidney Dis, 2009; 53:S11-21.

18. Thomas M, Viberti G, Groop P. Screening for chronic kidney disease in patients with diabetes: are we missing the point? Nat Clin Pract Nephrol, 2008; 4:2-3.

19. Holman RR, Paul SK, Bethel MA et al. 10-year follow-up of intensive glucose control in type 2 diabetes. N Engl J Med, 2008; 359:1577-89.

20. Bilous R. Microvascular disease: what does the UKPDS tell us about diabetic nephropathy? Diabet Med, 2008; 25:25-9.

21. Gaede P, Lund-Andersen $\mathrm{H}$, Parving $\mathrm{HH}$ et al. Effect of a multifactorial intervention on mortality in type 2 diabetes. N Engl J Med, 2008; 358:580-91.

22. Patel A, MacMahon S, Chalmers J et al. and ADVANCE Collaborative Group. Effects of a fixed combination of perindopril and indapamide on macrovascular and microvascular outcomes in patients with type 2 diabetes mellitus (the ADVANCE trial): a randomised controlled trial. Lancet, 2007; 370:829-40.

23. Patel A, MacMahon S, Chalmers J et al. and ADVANCE Collaborative Group. Intensive blood glucose control and vascular outcomes in patients with type 2 diabetes. N Engl J Med, 2008; 358:2560-72.

24. Zoungas S, de Galan BE, Ninomiya T et al. The combined effects of routine blood pressure lowering and intensive glucose control on macrovascular and microvascular outcomes in patients with type 2 diabetes; new results from ADVANCE. Diabetes Care, 2009; 32:2068-74

25. Ruggenenti P, Fassi A, Ilieva AP et al. Preventing microalbuminuria in type 2 diabetes. N Engl J Med., 2004; 351(19):1941-51.

26. Parving $\mathrm{HH}$, Lehnert $\mathrm{H}, \mathrm{BrC} \llbracket$ chner-Mortensen $\mathrm{J}$ et al. The effect of irbesartan on the development of diabetic nephropathy in patients with type 2 diabetes. N Engl J Med, 2001; 345:870-8.

27. Lewis EJ, Hunsicker LG, Clarke WR et al. Renoprotective effect of the angiotensin-receptor antagonist irbesartan in patients with nephropathy due to type 2 diabetes. N Eng J Med, 2001; 345:851-60.

28. Burney B, Kalaitzidis R, Bakris G. Novel therapies of diabetic nephropathy. Curr Opin Nephrol Hypertens, 2009; 18:107-11.

The authors would like to acknowledge Dr. Anne Reutens contributions to the manuscript. 